\title{
Extinguishment of Enclosed Gas Fires with Water Spray
}

\author{
RAGNAR WIGHUS
}

SINTEF-NBL Norwegian Fire Research Laboratory

$\mathrm{N}-7034$ Trondheim

Norway

\begin{abstract}
.
Experiments have been performed in a $2.5 \times 2.5 \times 5 \mathrm{~m}^{3}$ enclosure with various water spray nozzles fighting a $1 \mathrm{MW}$ propane fire.Ventilation is provided through an inlet opening at floor level, and an outlet opening at ceiling level. Fire induced ventilation has been examined. The fire source is propane forming an equivalent pool fire with dimensions 0.3 $x 1.3 \mathrm{~m}^{2}$. The nozzles produce sprays with a full cone coverage, with mean nominal water droplet diameter varying from about $0.5 \mathrm{~mm}$ to $1.6 \mathrm{~mm}$.

The results are presented as a heat balance for the water spray, the compartment and the ventilated smoke, by a ratio SHAR - Spray Heat Absorbtion Ratio. A general observation is that the fire is extinguished when the spray absorbs a certain fraction of the heat release rate. The extinction mechanisms seem to be a combination of inerting the combustion zone with evaporated water, and consequently a reduction of temperature. When the water spray absorbes only a lesser fraction of the released heat, the smoke temperature and the total heat flux to the compartment is considerably reduced. There is a distinct connection between water droplet size and the ability to extinguish the fire, in favour of the smallest droplets.
\end{abstract}

KEYWORDS: Fire, Enclosed, Gas, Extinguishment, Water, Droplet size.

\section{INTRODUCTION}

Water sprays are widely used for fire fighting in industrial areas, and are used for fire protection in the process industry and on offshore oil- and gas production platforms. No real quantification of the effect of water sprays as a fire fighting medium exists, and the water delivery is specified through standards and regulations, which are based on industrial experience. In process areas water spray is often used in deluge systems, intended to control a fire until the leakage of fuel has been shut down. For this purpose there is a need for quantification of the ability a certain spray system has to remove heat from the fire, and reduce the fire load to the constructions and process equipment. SINTEF NBL has studied extinguishment and control of enclosed hydrocarbon fires by with water sprays. A scale model of a module of an offshore platform is formerly used in studies of enclosed liquid hydrocarbon fire development. The model is instrumented to measure heat transfer, fire development and production of soot and gases from combustion $[1,2,3]$. This model is modified to withstand a water spray introduced in a fire, and is equipped with a propane burner instead of the liquid pool fire. A project 
"Active fire protection", financed by the Norwegian oil companies Norsk Hydro a.s, Saga Petroleum a.s. and Statoil a.s., and by the Royal Norwegian Council for Scientific and Industrial Research, was performed in 1988-90 [4].

Analysis of the interaction between a water spray and a fire environment is based on heat balances: for the water, for the air flowing through the model, and for the fire compartment. A characteristic fraction, the Spray Heat Absorbtion Ratio, characterizing the effect of a certain spray/compartment configuration is presented for various sprays with different mean droplet size.

\section{THEORETICAL BASIS}

\subsection{Heat Balance of a Fire Compartment}

The heat produced in a fire in an enclosure is either accumulated in the room or transported to the ambient. A major part of the heat is convected and radiated to the walls, ceiling and floor, and another large part is convected to the ambient through ventilation. A smaller part is radiated through openings.

In the first minutes of a fire is dominated by rapid transients, both in fire growth and accumulation of heat in the walls, ceiling and floor materials. Steady state occurs when the heat accumulation in the boundaries goes to zero. A graphical view of the heat balance of a fire room is shown in Figure 1.

The amount of heat removed by the water is dominated by the amount of water which is evaporated. The proportion of heat necessary to bring the water from the normal tap water temperature to the boiling point and the heat of evaporation is $\approx 1 / 6$. This means that the most effective way of taking heat out of a fire com-

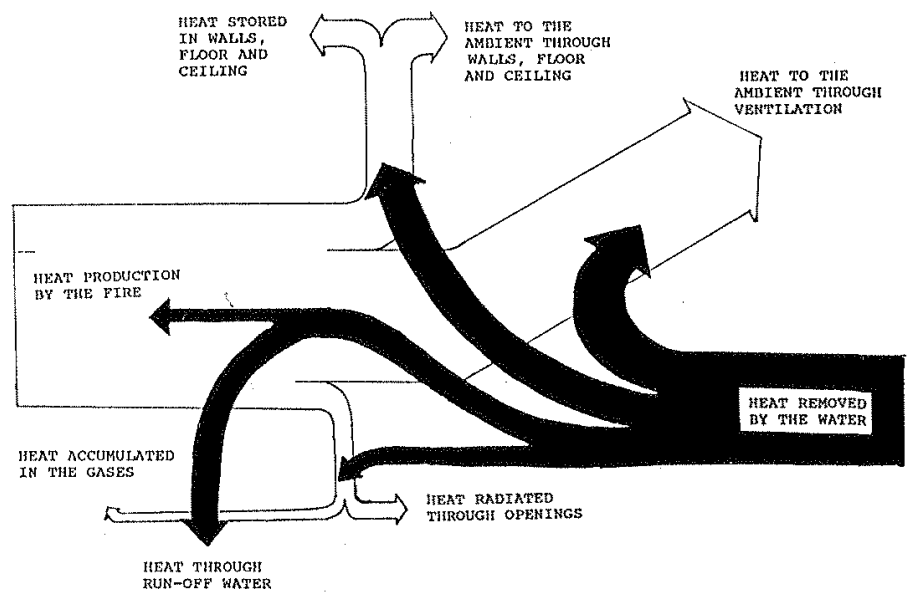

Figure 1. Heat balance of a room where a fire is developing. partment is to evaporate the water inside the room.

The water may influence the heat transfer from the fire to the compartment and the surrounding in several ways. The water may reduce the temperature of the gases inside 
the room and in the effluent gases. This leads to less heat transfer to the walls, the ceiling and the floor and to objects close to the outlet opening. Surfaces are directly cooled by impinging water droplets. The content of water droplets and vapour increases the absorptivity of the gases inside the fire room, and consequently this leads to reduced radiation from the flames to surfaces.

\subsection{Extinguishment of Fire}

The mechanisms of extinction of flames in a fire situation are supposed to be several, and a successful fire fighting often depends on more than one mechanism. The main theories of extinction are grouped in four: 1) - Cooling of the flames to a temperature where the chemical reactions can not maintained (below the fire point). 2) - Reduction in oxygen concentration to a level where reactions can not be maintained. 3) - Speeding up flow velocity to a level where the residence time of fuel and oxygen in combustible mixture is less than needed by the chemical reaction (blow-off). 4) - Adding components in the combustion zone which breaks the chain of chemical reactions by substitution with endothermal reactions.

The most probable mechanisms acting when water droplets are supplied in the combustion zone, is a combination of oxygen depletion by production of steam, and cooling by the evaporation of water. In complete mixed reactors, the water vapour concentration associated with extinction is $\approx 30 \%$ on mole basis. In a fire room, where the mixing is not as efficient as in a reactor, the critical global mole fraction of steam which leads to extinction is expected to be above $30 \%$ but still below $40 \%,[5,6]$.

\subsection{Effect of Water Droplet Size}

The ratio of surface area to volume of a droplet is proportional with droplet diameter, provided that the droplets are spherical. The rate of evaporation of one droplet is mainly governed by the temperature difference between the droplet and the surrounding gases, and the relative velocity. Small droplets supplied in the hot zone of the fire is the fastest way of cooling the fire. Using normal sprinkler technology, small droplets will evaporate before they reach the base of the fire, and they will evaporate in the upper part of the room. Most of the produced steam will follow the smoke through the exhaust opening. However, the rapid evaporation of the water may block the air supply by the expansion of evaporation, and the air drawn into the combustion zone may be recirculated from the upper part of the room. This can lead to oxygen starvation in the combustion zone, and consequently to extinction. This process is transient, and the location of the fire relative to the spray nozzle and the air supply- and outlet openings will dominate the result. On the other hand, large water droplets will survive in a hot environment for a long time; will have impact to penetrate a fire plume and will hit the fuel and the floor without being totally evaporated. The sprinkler technology utilizes this, as the purpose of the spray action usually is to wet the goods to be protected, to prevent fire spread. In oil and gas fires, the profit of wetting the fuel is usually not great, except for cooling liquid pool fires to a temperature below the flash point of the liquid.

Investigations done by Underwriter's Laboratories Inc. in 1955 [7], has shown that for 
small scale laboratory fires, a substantial difference in extinguishment effectiveness is found for water droplet sizes of $300 \mu \mathrm{m}$. Smaller droplets extinguished test fires with small amounts of water, as the required water discharge rates was much higher with larger droplets.

Factory Mutual Research Corporation (FMRC) has shown that liquid pool fires and spray fires in enclosures can be extinguished with small droplets. Keeping the fire and the water delivery constant, extinguishment occurred when the droplet size was reduced [5]. Results of various tests with Hexane pool fires in the corner of a $27.2 \mathrm{~m}^{3}$ room with a window on the wall opposite the pool fire, is shown in Table 1. Sprinkler nozzles, with

\begin{tabular}{cccccccc}
$\begin{array}{c}\text { Fuel pan } \\
\text { diameter } \\
m\end{array}$ & $\begin{array}{l}\text { Sprinkler } \\
\text { delay time } \\
\mathrm{s}\end{array}$ & $\begin{array}{l}\text { Water } \\
\text { discharge } \\
\text { rate g/s }\end{array}$ & \multicolumn{3}{c}{ Sprinkler nozzle orifice diameter } \\
& & & 11.0 & 8.36 & 6.69 & 5.57 & 4.17 \\
& & & & & & & \\
0.914 & 60 & 1080 & $\mathrm{~N}$ & $\mathrm{E}$ & $\mathrm{E}$ & & \\
0.914 & 60 & 707 & $\mathrm{~N}$ & $\mathrm{~N}$ & $\mathrm{~N}$ & $\mathrm{E}$ & \\
0.914 & 60 & 448 & & & $\mathrm{~N}$ & $\mathrm{~N}$ & $\mathrm{E}$ \\
0.762 & 75 & 448 & & $\mathrm{~N}$ & $\mathrm{~N}$ & $\mathrm{~N}$ & $\mathrm{~N}$
\end{tabular}

N: Not extinguished E: Extinguished

TABLE 1 Results of hexane fire extinguishment, from tests done by Factory Mutual Research Corporation /5/. different orifice diameter was used, and the pressure of the water was increased to obtain similar water discharge rate.The result of smaller orifice diameter and increased water pressure, is reduction of droplet size. A correlation for the median droplet diameter versus pressure and orifice diameter was found for the geometry of the used sprinkler nozzle [6]:

$\mathrm{d}_{\mathrm{r}}=\left(\Delta \mathrm{p} / \Delta \mathrm{p}_{0}\right)^{-1 / 3}\left(\mathrm{D} / \mathrm{D}_{0}\right)^{2 / 3}$

where $d_{r}$ : relative median droplet diameter $-, \Delta p:$ pressure at the nozzle, $\Delta p_{0}$ : reference pressure (of which the mean droplet diameter is known), D : orifice diameter, and $D_{0}$ : reference orifice diameter. This correlation may be used for geometrically similar nozzles, and it gives relative median droplet diameters. To obtain the real diameters one have to know the median droplet diameter produced by the reference nozzle. For the test nozzles used in the experiments at FMRC [5,6], the median droplet diameter was characterized by the correlation:

$\mathrm{d}_{\mathrm{m}}=1.076 \cdot \Delta \mathrm{P}^{-1 / 3} \cdot \mathrm{D}^{2 / 3}$

where $\mathrm{d}_{\mathrm{m}}$ : median droplet diameter in $\mathrm{mm}, \Delta \mathrm{P}$ : nozzle pressure drop in $\mathrm{kPa}$, $\mathrm{D}$ : orifice diameter in $\mathrm{mm}$. With the referred parameters $\Delta \mathrm{P}=17.2 \mathrm{kPa}$ and nozzle diameter $11.2 \mathrm{~mm}$, the correlation gives a reference mean droplet diameter $\mathrm{d}_{\mathrm{m}}=0.562 \mathrm{~mm}$, or $562 \mu \mathrm{m}$. This correlation is used to find droplet sizes where extinguishment was obtained, and the result is shown in Figure 2.

\subsection{The Spray Heat Absorption Ratio}

A concept for analyzing the effect of various water sprays on fires has been developed. It is based on the results of the FMRC tests $[5,6]$, but is adopted to the hydrocarbon fire test rig at 
SINTEF. The analysis is based on measuring the heat fluxes from the fire to the different parts of the fire room and its surroundings. For the non-extinguished fire, the heat release rate balances the heat losses to the walls, the ceiling and the floor, the heat convected by ventilation, the heat radiated through the openings of the room and the heat accumulated

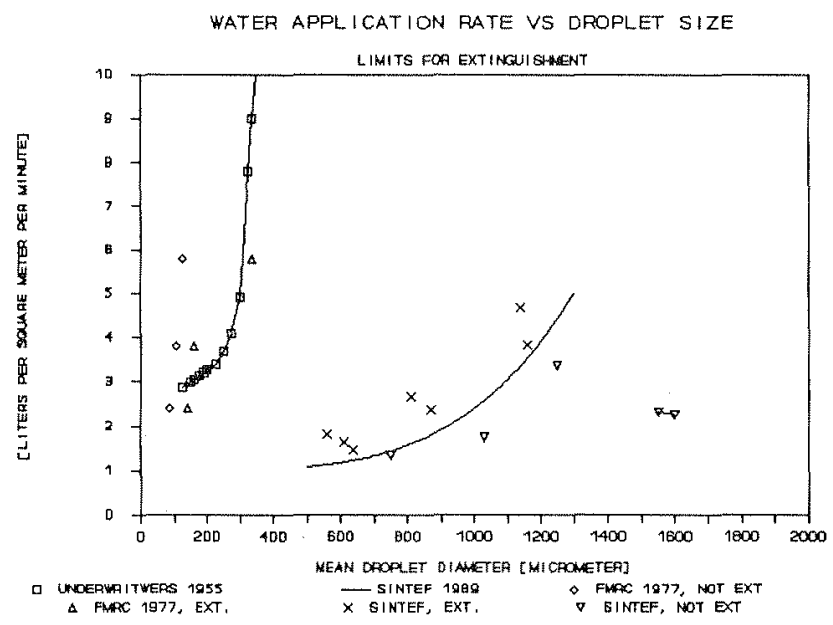

Figure 2

Extinguishment of various enclosed hydrocarbon fires with water droplets, References $/ 4,5,6,7 /$

in the gases contained in the room. If the same balance is set up after spray activation, the heat loss to the water is added to the heat losses, as the losses to the other parts of the room and the environment is reduced. A ratio of the heat loss to the room and environment, exclusive the water loss, characterizes the effectiveness of a water spray:

SHAR $=1-\left\{\left(Q_{\text {wall }}+Q_{\text {ceil }}+Q_{\text {floor }}+Q_{\text {vent }}\right) / Q\right\}$

where SHAR : Spray Heat Absorption Ratio, $Q$ : total heat release rate, $Q_{\text {wall }}$ : heat absorbed by walls, $Q_{\text {ceil }}$ : heat absorbed by the ceiling, $Q_{\text {floor }}$ : heat absorbed by the floor, $\mathrm{Q}_{\text {vent }}$ : heat convected by ventilation. The heat accumulated in the gases enclosed in the fire room, and the fraction of heat radiated through the openings of the room, are disregarded in the analysis. From earlier experiments in the same fire room, and from the tests done by FMRC, it is documented that these heat fractions are in the order of $0.1 \%$ of the total heat release. Another interpretation of SHAR can be expressed directly as:

$\mathrm{SHAR}=\mathrm{Q}_{\text {water }} / \mathrm{Q}$

where $Q_{\text {water }}$ : heat absorbed by the water. The heat absorbed by the water can be split in four parts: 1) - the heat necessary to bring the evaporated fraction of water from the supply temperature to the boiling point, 2 ) - the heat necessary to evaporate this fraction, 3) - the heat necessary to superheat the steam to the temperature of the exhaust gas, 4) - the heat necessary to bring the run off water from the supply temperature to its final temperature. 


\section{EXPERIMENTS}

\subsection{Parameter Variation}

The main variables in the experiments were the nozzle type, the water pressure and location of the nozzles, all giving the delivered water density. The heat output of the burner, the preburn time before spray activation and the ventilation rate of the fire compartment are other possible variables, but these are varied to make qualitative evaluations only. The model compartment has two openings, one air inlet at the floor level of the front wall, and an outlet at the ceiling level at the rear wall. A list of parameter variations, and some key numbers for identification of each test is given in Table 2. The preburn time of the fire in the model compartment is 5 minutes in the typical experiment. Then water is applied through a nozzle mounted central in the ceiling, heading directly at the propane burner. The fire starts at about $1 \mathrm{MW}$, and decreases to about $850-900 \mathrm{~kW}$ in the next 15 minutes. A description of the experiment set up is given in Figure 3.

\subsection{Heat Transfer Assess- ment}

The heat produced by the fire is transferred partly to the model itself and partly to the surrounding environment. The model has thick walls made

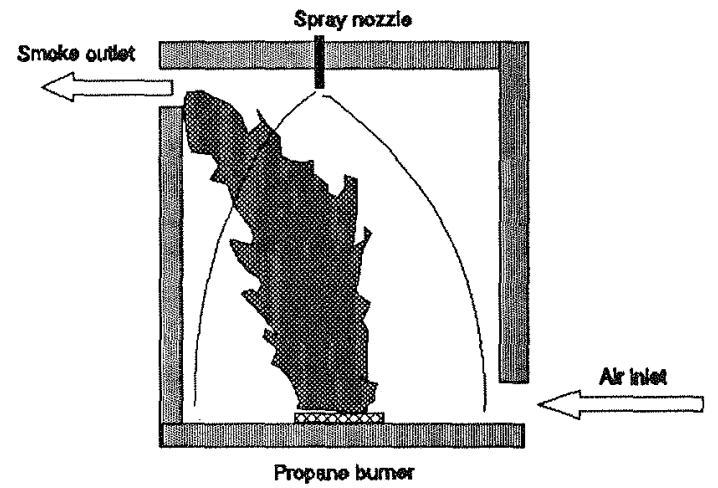

Figure 3 Experiment set-up in the SINTEF tests [4]. of insulating materials. The time to heat the model walls and ceiling to a stagnant temperature, where all the heat transported into the model is convected to the surroundings, is in the order of hours. However, the first period with rapid transients in heat transfer to the walls lasts about 5 minutes. The preburn time of the fire before water is applied is chosen to be 5 minutes, to assure equal initial conditions in every experiment. A view of heat balance for the model, as measured in the experiments, is shown in Figure 4. Ventilated heat loss is about $500 \mathrm{~kW}$ of the total heat release of 950 $\mathrm{kW}$ in the first 5 minutes. After activation of the spray, the fraction of heat through ventilation decreases to about $400 \mathrm{~kW}$. The next largest heat flux is to the walls and the ceiling, and then a fraction to the floor. Heat flux to the walls counts for about $300 \mathrm{~kW}$ the first 5 minutes, decreasing to about $180 \mathrm{~kW}$ after spray activation. The heat flux to the floor is shown separately, as the steel plates of on the floor gives away a large flux of heat just as the water hits the floor. This heat flux evaporates almost all the water flow in the first half minute, and is seen to be of great importance regarding instant extinction.

The heat flux through water which runs off the floor is also measured, and is a measure for the effectiveness of the water applied to the model. A large heat flux through water run off is telling that less water has evaporated in the model. The sum of the heat loss 


\begin{tabular}{|c|c|c|c|c|}
\hline \multirow[t]{2}{*}{ NOZZLE } & $\begin{array}{l}\text { PRESSURE } \\
\text { DROP AT } \\
\text { NOZZLE }\end{array}$ & $\begin{array}{l}\text { WATER } \\
\text { APPLICATION } \\
\text { RATE }\end{array}$ & $\begin{array}{l}\text { MEAN } \\
\text { DROPLET } \\
\text { DIAMETER }\end{array}$ & \multirow[t]{2}{*}{ RESULT } \\
\hline & bar & $1 /\left(\mathrm{m}^{2} \cdot \mathrm{min}\right)$ & $\mu \mathrm{m}$ & \\
\hline \multirow[t]{6}{*}{$\mathrm{HH} 7$} & 2.54 & 4.66 & 1130 & Extinguished \\
\hline & 2.42 & 3.83 & 1160 & Extinguished \\
\hline & 1.87 & 3.48 & 1250 & Not exting. \\
\hline & 1.84 & 3.36 & 1260 & Not exting. \\
\hline & 0.99 & 2.31 & 1550 & Not exting. \\
\hline & 0.95 & 2.26 & 1570 & Not exting. \\
\hline \multirow[t]{3}{*}{$\mathrm{HH}_{4}$} & 2.74 & 2.64 & 800 & Extinguished \\
\hline & 2.26 & 2.38 & 855 & Extinguished \\
\hline & 1.31 & 1.74 & 1025 & Not exting. \\
\hline \multirow[t]{4}{*}{$\mathrm{HH} 22$} & 7.12 & 1.81 & 550 & Extinguished \\
\hline & 5.53 & 1.63 & 595 & Extinguished \\
\hline & 4.58 & 1.45 & 635 & Extinguished \\
\hline & 2.79 & 1.35 & 750 & Not exting. \\
\hline
\end{tabular}

TABLE 2 List of experiments with key data

through ventilation, to the walls, the ceiling and the floor, and through the run off water, is shown, and can be compared with the total heat release of the fire. The difference between those is the heat of evaporated water.

\subsection{SHAR - the Spray Heat Absorbtion Ratio}

As mentioned in Chapter 2, the SHAR can be found in two ways. The most constituent way in the present experiment series is to use the heat balance of the model and the environment. The measurement of evaporated water is disturbed by water accumulation in the model compartment. This makes the estimate of evaporated water uncertain in the most transient period, just after water application. The SHAR of a two experiments which were not extinguished after water application is presented in Figure 5.

Increasing nozzle pressure gives increased SHAR. The SHAR value has a peak just at the moment of spray activation, reflecting the heat transfer from the model itself, especially the floor, to the water. The peak value is close to 0.6 with the highest nozzle pressure, and 0.5 with the lowest pressure. A general observation is that a spray which do not instantly absorb more than $60 \%$ of the heat released by the fire, will fail in extinguishment. Another observation made during the parameter variation is that if 
extinguishment is not obtained instantaneously, the SHAR characteristic for extinguishment is above 0.7 .

\subsection{Critical Parameters}

\section{for Extinguishment}

For the fire size and room configuration used in these experiments, a very sharp limit is found for instant extinguishment of the propane fire. This is shown graphically in Figure 6.

In all experiments the spray nozzle is positioned in the centre of the ceiling, heading downwards directly at the flame base. The effect of the spray when extinguishment occurs is that the flames becomes blue, flickering about, from one part of the compartment to another for then to disappear totally. The duration of this period was less than $10 \mathrm{~s}$ in experiments with large droplets, up to 25 $\mathrm{s}$ with the smaller droplets.

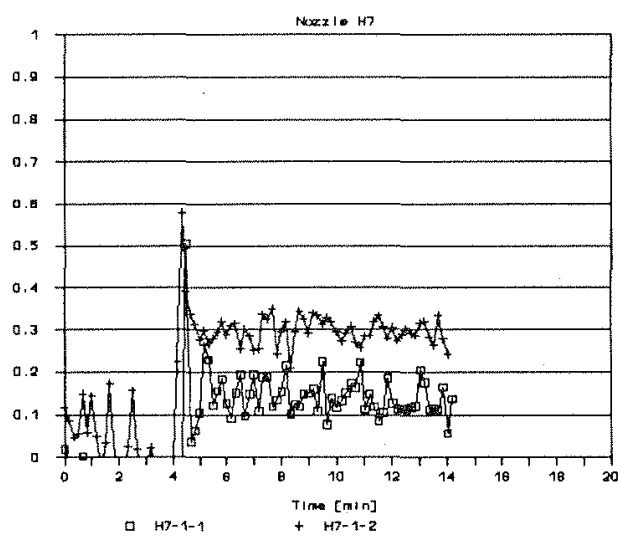

Figure 5 SHAR - Spray Heat Absorbtion Ratio - for experiments without extinguishment, using nozzle H7.

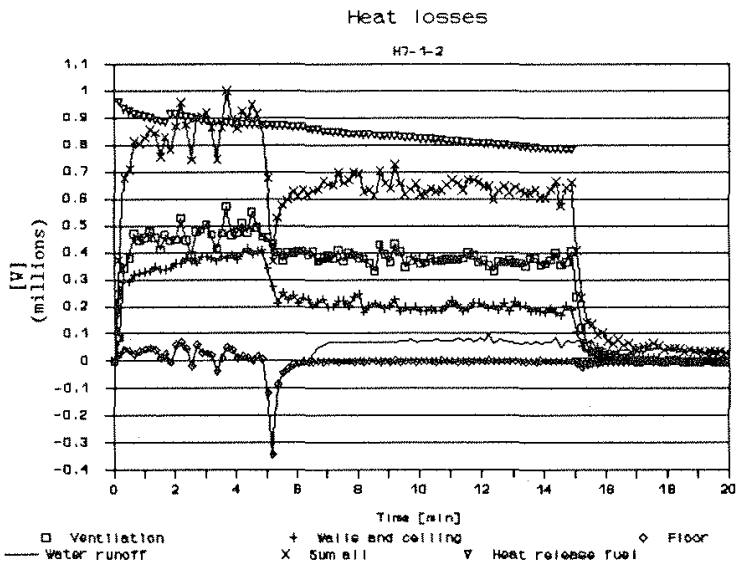

Figure 4 Heat fluxes as measured in experiment H7-1-2. 


\section{DISCUSSION}

\subsection{Extinguishment of Enclosed Gas Fires}

The absorption of heat from a fire by a water spray is a function of water discharge rate and mean water droplet size. In the experiment in a $30 \mathrm{~m}^{3}$ compartment, with ceiling mounted sprays, with full cone characteristic, with a propane fire with low exit velocity, the necessary water application rate to achieve extinguishment was reduced

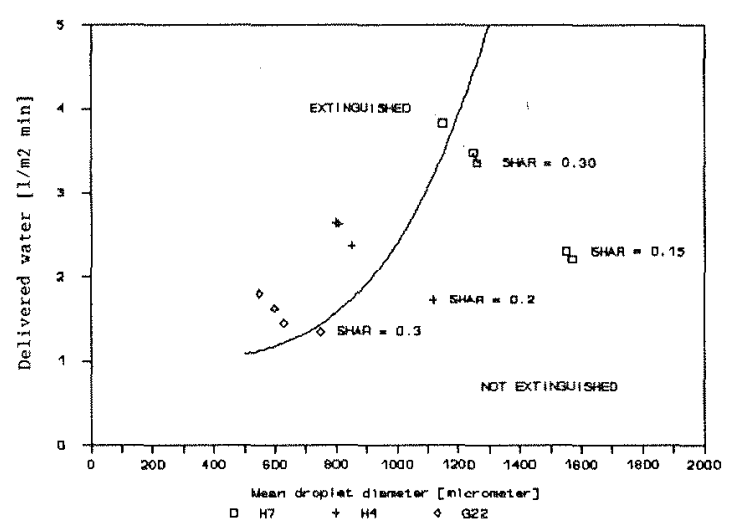

Figure $6 \quad$ Results of extinguishment tests for a propane fire about 1 $[\mathrm{MW}]$ in a $\left.30 \mathrm{rm}^{3}\right]$ compartment, with fire induced ventitation.

consistently at a droplet

size below $1000 \mu \mathrm{m}$ or $1 \mathrm{~mm}$. To extinguish a fire of about $1 \mathrm{MW}$ in this compartment, a water application rate of about $1.3 \mathrm{l} /\left(\mathrm{m}^{2} \cdot \mathrm{min}\right)$ is sufficient, when the mean droplet diameter is about $600 \mu \mathrm{m}$.

The required water application rate for extinguishment with a spray producing droplets with a mean diameter above $1000 \mu \mathrm{m}$ is more than 2.5 times larger, about $3.51 /\left(\mathrm{m}^{2} \mathrm{~min}\right)$.

The effectiveness of the spray action is also very dependent of the location of the spray nozzle versus the fire. A spray directly impinging the flame zone of a fire is much more effective than spray not impinging the base of the fire. However, the evaporation of water in direct contact with hot surfaces in the fire compartment may be sufficient to produce an inert atmosphere. The preburn time of the fire before spray activation will dominate the available heat accumulated in the model itself, and is in real life a function of detection or sprinkler characteristics. The difference in extinguishment limit between the SINTEF tests and former test done by Underwriters Laboratories [7] and Factory Mutual Research Corporation [5,6], may be explained:

A critical droplet size for extinguishment is larger when the spray impinges the flame zone directly, as in the SINTEF tests.

Different measurement technique for droplet size characterization may give different meán droplet size values. The test apparatus used by UL in 1955, the technique used by FMRC in 1977 and the tests done by Spraying Systems Corporation, $[8,9]$, may well give different values.

A problem may occur if a deluge system is activated to control a gas fire in an enclosure, and the preburn time is long enough to accumulate heat sufficient to produce 
an inert atmosphere inside the enclosure. Then the gas fire may be extinguished, and if the gas is still leaking, it may produce an explosive gas concentration. An explosion following a new ignition may have worse consequences than a fire controlled by the water spray.

\subsection{Control of Enclosed Gas Fires}

The mean temperature inside the enclosure and the temperature of the outflowing smoke gases can be reduced consistently through water spray action. In the $1 \mathrm{MW}$ fire, the temperature typically was reduced about $100^{\circ} \mathrm{C}$, from a mean temperature of 200 $300{ }^{\circ} \mathrm{C}$. Heat flux densities to the walls and the ceiling are reduced considerably. The soot concentration in the exhaust gas is also considerably reduced with spray action.

\section{CONCLUDING REMARKS}

It is demonstrated through experiments that there is a sharp limit for instant extinguishment of gas fires in enclosures. The main factors affecting the interaction of a water spray and a fire plume is the fire size, the discharge rate of water and the mean water droplet size. Ventilation rate and location of the fuel and the spray nozzle is also of great importance. Sprays with mean water droplet diameter less than $1 \mathrm{~mm}$ are far more effective in extinguishment than sprays with larger droplet sizes.

Small droplets is also favourable regarding control of a burning fire. The reduction of gas temperature and heat flux to the enclosure is larger with small droplets than with large ones. The SHAR value - the Spray Heat Absorbtion Ratio - is a useful parameter both to characterize the effectiveness of a spray regarding control of a fire, and to evaluate limits for extinguishment.

\section{REFERENCES}

1. Opstad, K.,Brandt, $\varnothing$. and Wighus, R.: Experimental Modelling of Liquid Pool Fires influenced by object, in a 1:4-scale Offshore Module. SINTEF report STF25 F89001, Trondheim, January 1989. (Restricted)

2. Opstad, K.,Brandt, $\varnothing$. and Wighus, R.: Experimental Modelling of Liquid Pool Fires in an Empty 1:4-scale Offshore Module. SINTEF report STF25 F89015, Trondheim, June 1989. (Restricted)

3. J.P.Stensaas, P.J.Hovde, and B.F.Magnussen: Physical Modelling of Enclosed Pool Fires Development of Empirical Correlations. Proceedings of the Second International Symposium on Fire Safety Science, 'Tokyo 1988, Hemisphere Publishing Corporation, 1989. ISBN 0-89116-864-8.

4. Wighus, R.: Active fire protection - Extinguishment of enclosed gas fires with water sprays. SINTEF report STF25 F90016, Trondheim, December 1990.(Restricted)

5. Hsiang-Cheng Kung: Cooling of Room Fires by Sprinkler Spray. Journal of Heat Transfer Vol. 99, August 1977.

6. Hong-Zeng You, Hsiang-Cheng Kung, Zhanxian Han: Spray cooling in room fires. Factory Mutual Research Corporation, Technical report FMRC J.I.OJ0N9.RA, March 1986.

7. The Mechanism of Extinguishment of Fire by Finely Divided Water. Underwrighter's Laboratories Inc. USA, 1955.

8. Particle size vs. volume percentage for fulljet nozzles. Spraying Systems Co., Private communications, 1991.

9. Spraying nozzles \& accessories, Spraying Systems Co. Industrial catalog 50 M, 1987. 